\title{
Nurses ability on implementing pain management through supervision model by head nurse
}

\begin{abstract}
Pain becomes cause most of the individuals seek medical help is a total of $73 \%$. Therefore nurses must have the ability in the management of pain. In fact, no all of nurses have the capability of being good in the management of pain. Head nurses having role to give education and counseling the through its supervision. The aim of this research is to look at the relationship of model supervision head nurses to the ability of associate nurse in the management of pain. A design research descriptive correlative with cross sectional approach. Sample as many as 39 associate nurses in inpatient RSUD Dr. M Zein Painan with purposive of sampling. The results is $(53.8 \%)$ of respondents indicated good results against supervision, (59\%) of respondents have quite high ability in the management of pain. There is strong correlation supervision against the ability of associate nurse in the management of pain $(\mathrm{p}=0.000 \mathrm{r}=0.595)$. There is strong correlation between variables confounding working time to the ability of associate nurses in the management of pain $(\mathrm{p}=0.030 \mathrm{r}=-.367)$. There is strong correlation between variables age to the ability of associate nurses in the management of pain $(\mathrm{p}=0.024, \mathrm{r}=-.340)$. Conclusion is model supervision by doing good will increase the capability of associate nurse in the management of pain. Recommendation to institutions service is training exercises supervision for the head nurse to improve implementation of supervision.
\end{abstract}

\author{
Volume 5 Issue 2 - 2018 \\ Lisavina Juwita, Elly Nurachmah, Atih \\ Rahayuningsih \\ Department of Nursing, Andalas University, Indonesia
}

Correspondence: Lisavina Juwita, Department of Nursing, Andalas University, Indonesia, Email lisavina_juwita@yahoo.com

Received: July 18, 2017 | Published: March 02, 2018

\section{Introduction}

Comfort (free from pain/controlled pain) is one indicator of nursing service quality. ${ }^{1}$ of the patients admitted to hospital, pain is the most common complaint experienced by patients. Pain with moderate to severe intensity complained by most hospitalized surgical patients that is as much as $73 \%$ that should be minimized pain. ${ }^{2}$

Bruster with a total of 3,162 patients from 36 NHS hospitals, showed that $33 \%(n=1042)$ patients (surgical medicines) experienced pain from moderate to severe intensity most of the time. Meanwhile, according to Whelan with prospective cohort study in 5,584 inpatients found that $59 \%$ of patients complained of pain, $28 \%$ reported severe pain, $19 \%$ reported moderate pain, while the rest reported mild pain. ${ }^{3}$

Pain management itself is a competency of a nurse but many nurses do not have optimal ability in pain management. Al-Shaer et al., ${ }^{1}$ study of nursing knowledge and skills in managing pain shows that not all nurses understand and do pain management properly.

One strategy to motivate nurses to work and pay attention to patient comfort is through the supervision of Head of Space. Supervision is part of the function of direction in the management function as one effective way to achieve goals in a hospital service order including the order of nursing services. Existing issues of headroom supervision have not been optimally performed. This study aims to identify the relationship of Head of Space supervision with the ability to manage the nurse's pain in the Inpatient Room.

\section{Research methods}

This research uses descriptive analytic correlation design with cross sectional approach. The sampling technique using total sampling technique with the number of samples in this study is as many as 39 people nurses implementing. This research was conducted in the surgery room and inner room as well as the inpatient classroom. Muhammad Zein Painan Questionnaire of supervision model of spatial leadership perceived by nurse executing modified from Manchester Clinical Supervision Scale (MCSS) questionnaire while nursing ability questionnaire in managing pain.

\section{Results}

\section{Characteristics of respondents}

The study respondents were on average 32 years old. of the nurse's educational background most of the practitioners $(89.7 \%)$ are D3 nursing. Executing nurses working in surgery and in-most disease $(84.6 \%)$ have never participated in training related to pain management. Based on length of service, the nurse has an average working period of 8 years.

\section{Head space supervision according to the implementer nurse perception in the surgery and disease in hospital Dr. M.Zein Painan}

Based on Table 1 more than half of respondents (53.8\%) showed good results on the supervision of head of space. Some of the less good are less feedback from the head of the room and the nursing nurse has difficulty taking the time to reflect the work along with the head of the room (normative), the nurse evaluates the supervision performed by the head of the room only limited supervision and monitoring, lack of direction and guidance from the head of space, And the head of space 
is less likely to identify the problem of pain management (formative), the nurse assesses the lack of punishment in pain management, the head of space is less consistent in the supervision of pain management (restorative).

Table I Distribution of frequency supervision of head of spaces according to perception of nurse executor $(n=39)$

\begin{tabular}{|c|c|c|c|}
\hline No & Variable & Number & Percentage (\%) \\
\hline \multirow[t]{4}{*}{1} & Supervision & & \\
\hline & Great & 21 & 53.8 \\
\hline & Poorly & 18 & 46.2 \\
\hline & Sub variable & & \\
\hline \multirow[t]{3}{*}{2} & Normative & & \\
\hline & Great & 22 & 56.4 \\
\hline & Poorly & 17 & 43.6 \\
\hline \multirow[t]{3}{*}{3} & Formative & & \\
\hline & Great & 21 & 53.8 \\
\hline & Poorly & 18 & 46.2 \\
\hline \multirow[t]{3}{*}{4} & Restorative & & \\
\hline & Great & 24 & 61.5 \\
\hline & Poorly & 15 & 38.5 \\
\hline
\end{tabular}

Ability nurse executor in pain management in the surgery and disease in hospital Dr. M. Zein Painan

Table 2 shows that more than half $(59 \%)$ of respondents have a high ability in pain management. Among the three sub-variables of ability, knowledge variable is the highest variable frequency that is equal to $51,3 \%$.

Table 2 Frequency distribution of nurse ability implementing in pain management $(n=39)$

\begin{tabular}{|c|c|c|c|c|}
\hline No & Variable & Category & $f$ & $\%$ \\
\hline \multirow[t]{3}{*}{ I } & $\begin{array}{l}\text { Ability nurse implementing in the } \\
\text { management of pain }\end{array}$ & High & 23 & 59 \\
\hline & & Low & 16 & 41 \\
\hline & Sub variable & & & \\
\hline \multirow[t]{2}{*}{2} & The ability knowledge & High & 20 & 51.3 \\
\hline & & Low & 19 & 48.7 \\
\hline \multirow[t]{2}{*}{3} & The ability attitude & High & 16 & 41 \\
\hline & & Low & 23 & 59 \\
\hline \multirow[t]{3}{*}{4} & The ability skills & High & 19 & 48.7 \\
\hline & & Low & 20 & 51.3 \\
\hline & Total & & 39 & 100 \\
\hline
\end{tabular}

Head of spatial supervision relation to nursing ability implementing in pain management

Table 3 shows the headroom supervision has a significant correlation to the nurse's ability to manage pain with moderate strength.
Table 3 Relationship of head of space supervision to ability of nurse in pain management July $2014(\mathrm{~N}=39)$

\begin{tabular}{cccccc}
\hline Variable & Ability & & Total & $\mathbf{p}$ & $\mathbf{r}$ \\
\hline & High & Low & & & \\
Supervision & & & & & \\
Great & 18 & 3 & 21 & $0.000 *$ & 0.595 \\
Poorly & 5 & 13 & 18 & & \\
\hline
\end{tabular}

\section{Multivariate analysis}

In the first step found all independent variables of supervision relate to dependent variables and two confounding variables, namely age and employment associated with independent variables.

Table 4 shows the variables that most contribute to the nurse's ability to manage pain are normative supervision. The result of analysis got Odds Ratio (OR) from supervision variable is 9,671 means normative supervision will increase ability of nurse executor in pain management as much as 10 times higher.

Table 4 Logistic regression result of correlation model relationship of head of space with nurse's ability in managing pain $(n=39)$

\begin{tabular}{|c|c|c|c|c|}
\hline & Variable & $P$ wald & Sig & $\operatorname{Exp}(B)$ \\
\hline \multirow[t]{4}{*}{ Step I } & Age & 0 & 0.986 & 1.02 \\
\hline & $\begin{array}{l}\text { Years of } \\
\text { services }\end{array}$ & 1.264 & 0.261 & 0.444 \\
\hline & Normatif & 3.96 & 0.047 & 7.176 \\
\hline & Formatif & 0.177 & 0.674 & 1.512 \\
\hline \multirow[t]{3}{*}{ Step 2} & $\begin{array}{l}\text { Years of } \\
\text { services }\end{array}$ & 3.263 & 0.071 & 0.437 \\
\hline & Normatif & 6.147 & 0.013 & 8.712 \\
\hline & Restoratif & 4.668 & 0.031 & 7.867 \\
\hline \multirow[t]{2}{*}{ Step 3} & Normatif & 7.645 & 0.006 & 9.671 \\
\hline & Restoratif & 3.895 & 0.048 & 5.163 \\
\hline
\end{tabular}

\section{Discussion}

\section{The relationship of nurse characteristics to the nurse's ability to manage pain}

The result of statistical test showed that there was a significant correlation between age and nurse ability in pain management. The same thing studies say that younger nurses have a more positive outlook than middle-aged nurses on the choice of nursing practice. This opinion is reinforced by Ampomah that there is a relationship between nursing age and nurse confidence that patient's pain response is a subjective response so that the assessment of the patient's complaint is a valid assessment. This shows that age affects one's beliefs and affects one's response to others.

According to Notoadmojo ${ }^{4}$ age affects the capability and mindset of a person. The more ages the more will develop the ability to catch and the mindset so that the knowledge gained better. In adulthood individuals will play an active role in society and social life. The more mature the age wiser in doing so many things that increase knowledge. 
The correlation between the working period and the nurse's ability to manage the pain shows a negative direction, the longer the nurses work the lower their ability to perform pain management. This is different from that expressed by Bowles and Young in Brunero et al., that there is a relationship between the length of work and the need for formative supervision. They found that somebody with a relatively small amount of work had a need for increased formative supervision. The differences in the results of this study may be due to new nurses having good knowledge and attitude towards pain management whereas long-term nurses tend to be less pain management, have less favorable attitude toward pain management, tend to assess the management of pain will not be effective to reduce pain so that Nurses rarely manage pain. This results in a decrease in a person's ability to do the job.

The result of statistic test showed that there was no significant relationship between sex and nurse ability in pain management. It agrees with Robbin et al., ${ }^{6}$ which states there is no difference between men and women in solving problems, analytical skills, competitive motivation and learning ability. The insignificant relationship can be influenced by the motivation of each nurse; female nurse and man have the same motivation because the head of space does not distinguish the gender in giving direction, guidance and motivation.

The result of statistic test showed that there was no significant correlation between educational level and nurse ability in pain management. Siagian ${ }^{7}$ explains that formal education involves intellectual ability related to the ability of individuals to accomplish tasks in their work. The results above are different from the research Mubarak and Chayatin ${ }^{8}$ which states that knowledge is influenced by educational factors. Pain management conducted by nurses is integrated in nursing care in pain patients. Pain management conducted by nurses ranging from assessment to pain evaluation has been taught in formal education both at the level of DIII and in S1 nursing. So the concept of nurses in the room has gained knowledge during the education level. This resulted in the absence of differences in the ability of nurses in the management of pain between nurses with background DIII and S1 Nursing

The result of statistic test showed that there was no significant relationship between training with nurse ability in pain management. The results of this study concurred with Zakiyah ${ }^{9}$ study which states that there is no significant relationship between training with the implementation of fluid administration interavena. However, contrary to Mangkunegoro research which explains that training is an activity that is held to increase the mastery of knowledge, skills and attitude as an employee.

The result of statistical test showed that there was a significant correlation between the working period and the nurse's ability in pain management. The results of research supported by research Lutfi $^{10}$ hat the working period associated with nurse's ability in triase. The period of work will cause someone experienced in doing a job. This is reinforced by Mangkunegoro improving the quality or ability of a person can be achieved through experience, education, training and development.

\section{The relationship of headroom supervision to the nurse's ability to manage pain}

The results of the research in supervision there is a significant correlation to the ability of nurses in the management of pain. Abilities are a born-or-learned trait that allows a person to complete his work. ${ }^{11}$
The ability of nurses in managing pain is the basic thing in doing nursing care in patients with pain. This has an impact on the nursing service provided to the patient.

According to the results of research the ability of nurses in the management of pain is only partially that has a high ability. This indicates that the nurse has not fully possessed good knowledge, attitudes and skills regarding pain management. A study conducted by Al-Shaer on nurse knowledge and skills in managing pain explained that nurse knowledge about pain management is still low and nurse attitude is not good to management of pain. Strategies that can be done to overcome this problem is by doing effective clinical supervision.

According to Kilminster \& Jolly ${ }^{12}$ supervision has three functions: education for knowledge and skills development, providing group support and stress relief for nurses and promoting professional accountability. This is in accordance with the supervision model of Proctor that supervision has three functions, namely the formative function of learning activities for skills development which is the basic thing of the supervision itself, the normative function of developing standards and norms to achieve quality patient service, Restorative is to provide support to staff to improve services. This is reinforced by Slainte and Socialta ${ }^{13}$ and Pitman ${ }^{14}$ who stated that continuous supervision can improve professionalism and personal development as well as commitment to continuous learning.

\section{Normative supervision}

The result of the research on the normative component shows that the nurse of the implementer perceives the normative supervision well. Proctor (1989) explains that normative supervision is the supervisor responsible for professional staff work. Normative supervision aims to improve individual nursing services, improve nursing practice, and improve job satisfaction.

The result of the research on the normative component shows that the nurse of the implementer perceives the normative supervision well. Proctor (1989) explains that normative supervision is the supervisor responsible for professional staff work. Normative supervision aims to improve individual nursing services, improve nursing practice, and improve job satisfaction.

\section{Formative supervision}

The results of the research on the formative component showed good results. Proctor (1989) explains that the formative component of the supervisor provides direction and feedback to the implementing nurse to improve the skills, theoretical knowledge and attitudes so that the executing nurse is expected to become a competent practitioner. According to Proctor (1989) the formative component has the goal of improving knowledge, learning, professionalism enhancement, improving confidence, increasing knowledge of patient rights, competent and creative, improving communication skills.

This is reinforced by Pitman, ${ }^{14}$ Allen \& Armorel $^{15}$ and research conducted by Brunero \& Panbury ${ }^{5}$ stated that the formative aspect focuses on developing the knowledge and skills of staff, as well as reflecting on the practices already implemented so as to enable staff to work in accordance with Standards that apply as aspects of responsibility in practice. According to Brunero \& Panbury ${ }^{5}$ that the formative component is the basis of clinical supervision activities. The main outcome of this activity is the improvement of knowledge, awareness and motivation, as well as creation and innovation. 
According Hyrkas ${ }^{16}$ corroborates this research that supervision can improve leadership, communication skills, self-development, knowledge and coping. The same is expressed by Jones that supervision can improve interpersonal learning and self-understanding. Magnuson also revealed the same thing that supervision can improve the ability of nurses in performing nursing care to patients by improving nurse confidence in making decisions.

\section{Restorative supervision}

The last component is restorative; the results showed that the nurse perceives restorative supervision well. Proctor (1989) explains that restorative supervision is a supervisor providing support, listening, providing moral support and assisting in resolving conflicts or doubts from nursing nurses. The purpose of this restorative component according to Proctor (1989) is to improve comfort, empathy, increase confidence, resolve conflicts, improve relationships with nurses, understand colleagues, support, improve coping, and job satisfaction.

Non-optimal assessment of the normative component ie less feedback from the head of the room and the implementing nurse has difficulty taking time for reflection of work along with the head of space. Meanwhile, the poor perception of the formative component of the executing nurses assessed the supervision performed by the head of the room was limited to supervision and monitoring, lack of direction and guidance from the head of space, and the head of space did not identify the problem of pain management. While the poor perception of the restorative component of the nurses assessed the lack of punishment in the management of pain, the head of the space is less consistent in the supervision of pain management.

The results of the three supervisory functions are normative, formative and restorative showed that the restorative supervision is the most dominant component performed by the head of space. This is consistent with research by Brunero \& Panbury ${ }^{5}$ that restorative supervision is a more frequent activity by supervisors. According to Brunero \& Panbury ${ }^{5}$ restorative supervision can reduce anxiety and conflict, build good interpersonal relationships, and improve coping skills.

\section{The association of variables that contribute to the nurse's ability to manage pain}

Variables related to the nurse's abilities in the management of pain are age, length of service, normati supervision, formative and restorative. The variable that most contribute to the nurse's ability to manage pain is normative supervision. Normative function is to promote professional accountability in performing health services to patients.

Normative supervision is linked to the supervisor's ability to maintain good staff performance by creating a conducive working environment, creating a plan, identifying the needs and problems needed to provide further support, creating patient safety, maintaining existing standards and trusting staff It can improve professionalism and create quality service quality. ${ }^{14}$

Based on the research that researchers do obtained results that normative supervision is done well will improve the ability of nurses in the management of pain. Research by Brunero and Panbury ${ }^{5}$ on the purpose of Proctor's supervision shows that supervision has a goal to improve nurses' ability to perform nursing care, improve individual nursing services, and improve nursing practice. Improvement of nursing practice especially pain management will improve the abilities and skills of nurse implementers.

\section{Conclusion}

More than half of the respondents showed a good perception of headroom supervision, had high pain management abilities. The majority of the study respondents had a nursing background of D3 nursing background with an average working life of 8 years and had never received training and averaged 32 year. ${ }^{17-19}$

The supervisory activities performed by the head of space based on the Proctor model have a significant correlation to the nurse's ability to manage pain with the strength of the relationship. The ability of the implementing nurse also correlates with work and age.

Proper nursing supervision based on the Proctor model can improve the nurse's ability to manage pain. This means that the better the supervision performed the better the nurse's ability to implement and this will affect the nursing services provided to patients.

\section{Suggestion}

The head of the nursing department may provide training in the clinical supervision of the head of the chamber to improve the ability to supervise and establish an operational policy and standard related to the supervisory activities performed by the head of space. The chamber head can improve supervision activities and understand the supervision activities as a directive function and provide support and guidance on the application of nursing action procedures to ensure the quality of nursing actions.

It is necessary to study in other populations using pain management instruments that researchers use so as to obtain validity and reliability are standard for this instrument. Similarly, MCSS supervision instruments can be reused by modifying and altering invalid statements to obtain standard instruments for assessing headroom supervision. Need to do further research about the relationship of ability with the implementation of pain management and factors - factors that mempngaruhi pain management implementation.

\section{Acknowledgements}

A big thanks to the Dean of the Faculty of Nursing Andalas University; Head of Master Program of Nursing Faculty of Nursing University of Andalas; Director of RSUD Dr. M.Zein Painan; Head of Nursing Section who has assisted in the research process at RSUD Dr. M.Zein Painan and Mother/Father of Academic Staff of Nursing Study Program of Faculty of Nursing Andalas University of Padang and to fellow colleagues during the education of Nursing Master Program of Nursing Leadership and Nursing Management Faculty of Nursing University of Andalas, who has provided support and assistance in completing this research.

\section{Conflict of interest}

None.

\section{References}

1. Nursalam. Nursing Management: Application in Professional Nursing Practice. $2^{\text {nd }}$ ed. Jakarta: Salemba Medika; 2008. 
2. Al-Shaer D, Hill PD, Anderson MA. Nurses' Knowledge and Attitudes Regarding Pain Assessment and Intervention. Medsurg Nurs. 2011;20(1):7-11.

3. Roden A, Sturman E. Assessment and management of patients with wound-related pain. Nurs Stand. 2009;23(45):53-58.

4. Notoatmodjo, Soekidjo. Education and Health Behavior. Jakarta. 2003.

5. Brunero S, Parbury JS. The effectiveness of clinical supervision in nursing: an evidenced based literature review. Australian Journal of Advanced Nursing. 2014;25(3).

6. Robbin P Stephen, Timothy A Judge. Organizational Behavior. 2009;1(12).

7. Siagia SP. Tips to improve work productivity. Jakarta.

8. Mubarak WI, Chayatin N. Basic Human Needs Textbook; Theory and application in practice. 2007.

9. Zakiyah A. Effect of supervision of spatial leadership on the implementation of intravenous fluid administration at Sidoarjo Regional Public Hospital. University of Indonesia. 2012.

10. Lutfi Amhad Faizal, Susilo Cipto, Rohmah Nikmatur. Old Relationship the working period of health workers with the ability of hospital triage in Emergency. 2015.
11. Gibson JL, Ivancevich JM, Donnelll JH. Organization, Behavior, Structure. Gelora Aksara Pratama; 2009. Indonesia.

12. Kilminster SM, Jolly. Effective supervision in clinical practice settings: a literature review. Ireland: Blackwell Science Ltd. Medical Education. 2000;34:827-840.

13. Slainte, Soisialta. Clinical Supervision for mental health nurses in Northern Ireland. Best Practice Guidelines.

14. Pitman S. Handbook for clinical supervision: nursing post graduate program. Dublin. 2011

15. Allen Armorel. Professional/clinical supervision handbook for allied health professionals. 2010 .

16. Hyrkas K. Clinical Supervision and Quality Care. Tampere.

17. A.A Anwar King Mangkunegara, Human Resource Management. Company, Bandung. 2004.

18. AA Anwar King Mangkunegara. Planning and Development. Human Resource Management. Bandung. 2006.

19. Ampomah DK. Knowledge, attitudes and beliefs about pain management: A comparative study of united states-born and west african-born nurses working in the united states. Pro Quest Dissertations and Theses. 2009. 